\title{
A Novel Topical 2\% Povidone-Iodine Solution for the Treatment of Common Warts: A Randomized, Double-Blind, Vehicle-Controlled Trial
}

\author{
Kara Capriotti $\cdot$ Kevin P. Stewart · Jesse S. Pelletier · Joseph Capriotti
}

To view enhanced content go to www.dermtherapy-open.com

Received: September 28, 2015 / Published online: November 3, 2015

(C) The Author(s) 2015. This article is published with open access at Springerlink.com

\section{ABSTRACT}

Introduction: Verruca vulgaris, also known as common warts, are benign skin growths caused by infection of the skin by human papillomavirus. Warts are common in both childhood and adulthood and are spread by direct contact or autoinoculation. Treatment options vary from locally destructive methods to immuno-modulatory therapy. Common warts are often resistant to treatment. Though many remedies exist, there is no consensus therapy backed by randomized-controlled clinical trials that are FDA approved for the

Electronic supplementary material The online version of this article (doi:10.1007/s13555-015-0086-1) contains supplementary material, which is available to authorized users.

K. Capriotti · K. P. Stewart · J. S. Pelletier .

J. Capriotti $(\square)$

ALC Therapeutics, LLC, Springhouse, PA, USA

e-mail: jacapriottimd@gmail.com

K. Capriotti

Bryn Mawr Skin and Cancer Institute, Rosemont, PA, USA

K. P. Stewart · J. S. Pelletier · J. Capriotti Plessen Ophthalmology Consultants, Christiansted, VI, USA treatment of verruca vulgaris. We describe here the results of a small, randomized, double-blind, vehicle-controlled Phase II clinical trial with a novel topical agent for the treatment of common warts.

Methods: Twenty-one patients aged 8 years and older were enrolled in this single-center, randomized, double-blind, vehicle-controlled Phase II clinical trial to assess the efficacy, safety and tolerability of twice-daily application of a novel $2 \%$ topical povidone-iodine solution in a dimethyl sulfoxide vehicle for 12 weeks duration. Patients were block randomized into two groups consisting of 14 patients in the active arm and 7 patients in the vehicle only arm. All patients were evaluated at baseline, week 4, 8 and 12 and the results compared for overall Global Aesthetic Improvement Scale (GAIS) improvement.

Results: There were a total of 21 patients included in the study. Sustained improvement in the GAIS scale was observed at the final week 12 exam visit in $77 \%$ of subjects in the treatment arm and $33 \%$ of patients in the control arm. There were no serious safety or tolerability issues reported. 
Conclusion: Twice-daily

topical

povidone-iodine solution in the novel vehicle employed for this study is an effective, safe and easy-to-use treatment for common warts. Further study of this agent in expanded Phase II and Phase III clinical trials is warranted.

Funding: ALC Therapeutics LLC.

Keywords: Common warts; Human papillomavirus; Povidone-iodine (PVP-I) solution; Verruca vulgaris

\section{INTRODUCTION}

Verruca vulgaris, also known as common warts, are benign skin growths caused by a viral infection of the skin. It is a worldwide infection that affects $7-12 \%$ of the population [1]. The cause of the condition is the human papilloma virus (HPV), which is a double-stranded, circular, supercoiled DNA virus enclosed in an icosahedral capsid and comprising 72 capsomers. There are more than 70 genotypes of HPV, and the genotypes are referenced by numbers. The common wart is most frequently caused by genotypes HPV-1, 2, 4, 27 and 57. Warts are prevalent in both childhood and adulthood and are spread by direct contact or autoinoculation. Verruca vulgaris typically occurs on the back of fingers or toes and on the knees, but they may occur anywhere on the skin or mucosal surface. Treatment is recommended for patients with extensive, spreading, or symptomatic warts [2]. Many patients feel the condition is socially stigmatizing. Treatment methods that are commonly employed include topical agents, intralesional injections, systemic agents, cryotherapy, laser, electrodessication and surgical excision, although common warts can be resistant to treatment [3, 4]. Clinical evidence favoring one therapeutic route over another is limited [5].

Iodophor preparations are commonly used in all medical specialties for skin antisepsis prior to percutaneous procedures and surgery [6]. Primarily iodophors work by delivering active molecular iodine to target tissues through enhanced aqueous solubilization. The most commonly used iodophor is povidone-iodine. Povidone-iodine kills microorganisms including bacteria, viruses, yeasts, molds, fungi and protozoa [7, 8]. In this randomized, double-blind, vehicle-controlled study, we utilized a novel 2\% PVP-I solution in a topical dimethyl sulfoxide vehicle twice daily for the treatment of common warts.

\section{METHODS}

The trial protocol and informed consent documents were approved by an Institutional Review Board experienced in both adult and pediatric studies. All procedures followed were in accordance with the ethical standards of the responsible committee on human experimentation (institutional and national) and with the Helsinki Declaration of 1964, as revised in 2013. Twenty-one patients aged 8 years and older were included in this single-center, randomized, double-blind, vehicle-controlled phase- 2 proof-of-concept study. The examiner determined the diagnosis of common warts clinically. Informed consent was obtained from all participants or participants' guardian if less than age of consent after explaining in detail the purpose and procedure of the treatment. Healthy individuals were deemed eligible for participation if they had at least one but not exceeding ten common warts. Warts located in the following areas did not qualify patients for 
inclusion in the study: the eye area (including eyelids), lips, mouth cavity, nasal cavity, inner ear, palms of the hands (including periungual area), soles of the feet (including periungual area), or the anogenital area. Those patients with prior treatment to the wart within the last 30 days were excluded, as were immunosuppressed and pregnant populations. Fourteen patients were allocated into the active arm (2\% PVP-I in vehicle solution twice daily) and seven patients were allocated into the vehicle-control solution arm twice daily, for a duration of 12 weeks in each arm. Both active drug and vehicle solution were made via a licensed GMP compounding pharmacy and matched for both color and consistency. Patients were evaluated at baseline, weeks 4,8 , and 12 with paring done at each visit. Global Aesthetic Improvement Scale (GAIS) scores were used as the benchmark for efficacy analysis. The GAIS is a 5-point scale rating global esthetic improvement in appearance, compared to pretreatment, as judged by the investigator. GAIS scoring for individual warts at each visit was as follows: very much improved $(+3)$, much improved $(+2)$, improved $(+1)$, no change $(0)$ and worse $(-1)$. Improvement was defined as a decrease in the diameter and thickness of the wart before paring was performed.

\section{RESULTS}

Twenty-one patients were enrolled in this study. Of the fourteen patients enrolled in the active arm, thirteen completed the study. For patients randomized into the active arm of treatment, 10/13 (77\%) demonstrated sustained improvement in the GAIS scale score, defined as an overall positive score derived from the summation of individual assessments at the Week 4, 8 and 12 visits. Sustained improvement was defined as wart showing decreased diameter and thickness from baseline. In the $3 / 13$ patients in the active arm that did not show sustained improvement, the patients' warts remained stable in size, and there were no additional warts at the sites observed. Each of the patients was followed through week 12 and there were no recurrences of warts that cleared before the 12-week time period. Subjective tolerability was assessed using a grading scale for stinging, burning and itching as reported by the patient. Zero patients reported these, respectively. Adverse side effects such as erythema, scaling and dryness were assessed by the examiner, with $2 / 13 \quad(15 \%)$ patients demonstrating mild dryness.

Of the seven patients enrolled in the vehicle-controlled arm, six patients completed the study. 2/6 (33\%) warts showed sustained improvement in the GAIS scale score, 2/6 (33\%) showed a worsening of the GAIS scale score and 2/6 (33\%) showed no change from baseline. Subjective tolerability was assessed using a grading scale for stinging, burning and itching as reported by the patient. Zero patients reported these, respectively. Adverse side effects such as erythema, scaling and dryness were assessed by the examiner, with 1/6 (17\%) patients demonstrating mild dryness.

\section{DISCUSSION}

Though various treatments are currently in use for common warts, no single therapy has emerged as effective in all cases. Purely destructive methods, such as liquid nitrogen (cryotherapy) and salicylic acid formulations either alone or in combination are the most commonly utilized methods [9, 10]. Immuno-modulating agents are also commonly employed off-label, such as oral 
cimetidine, injectable candida antigen, levamisole and imiquimod [11-13]. These agents are believed to up-regulate a Type IV hypersensitivity reaction but are not effective in all patients [14]. Intralesional bleomycin and 5-fluorouracil are painful to inject and carry risk of significant side effects such as necrosis [15, 16]. Duration of treatment is often lengthy regardless of modality, requiring several months of treatment and numerous painful procedures in an office setting. There is scant evidence that any single therapy is useful in every clinical situation [17].

Low-dose (i.e., less than the commonly used 10\%) PVP-I solutions have not been well studied in dermatology. Most dermatological literature describes skin antisepsis with 10\% povidone-iodine [18]. There have been some anecdotal reports of efficacy in the treatment of onychomycosis including one case report using a similar formulation to that under study in this report [19]. There have been several studies of low-dose PVP-I employed in otology and ophthalmology, though none have described any novel vehicle formulations that are capable of penetrating an intact skin or mucosal surface [20-22]. PVP-I solutions have shown excellent in vitro efficacy against enveloped model viruses as well as some non-enveloped human viruses, e.g., adenovirus and polyomavirus [23]. We report here the first randomized, controlled human clinical trials with low-dose PVP-I in a vehicle optimized for skin penetration.

The use of PVP-I at relatively lower concentrations than commonly employed in surgical antisepsis is new in dermatology. In particular, the development of novel formulations useful when administered in multiple doses has gained recent interest for chronic, difficult-to-treat infections in both skin and nails. These new agents based on PVP-I are useful for all microorganisms including bacteria, viruses, yeasts, molds, fungi and protozoa [24]. Their utility against HPV infections derives from its non-specific mechanism of action. PVP-I poisons electron transport, inhibits cellular respiration, destabilizes membranes, inhibits protein synthesis and denatures nucleic acids in the HPV virus and in virus-infected host cells. Resistance is very unlikely to develop given its non-specific means of inhibiting viral replication.

The study had some limitations that should be addressed if any further studies are planned. Most notably the patient sample size was inadequate to provide a base for meaningful statistical analysis, though a trend towards efficacy and a clear indication of safety was demonstrated. The solution formulation used in the trial requires $1-2$ min to dry completely, making it difficult for optimal compliance in the pediatric population. We suspect the contact time of the drug to skin was limited due to this issue, and have already developed a gel formulation for use in future studies.

\section{CONCLUSION}

This novel PVP-I formulation appears to be an effective, safe and well-tolerated treatment of common warts in both children and adults. Further study in expanded Phase II/III trials are warranted to develop new therapies for these common, difficult-to-treat infections. Additional study with a gel formulation may elaborate a variety of effective therapies for difficult-to-treat skin and skin structure infections.

\section{ACKNOWLEDGMENTS}

Sponsorship and article processing charges for this study were funded by ALC Therapeutics 
LLC. All named authors meet the International Committee of Medical Journal Editors (ICMJE) criteria for authorship for this manuscript, take responsibility for the integrity of the work as a whole, and have given final approval for the version to be published.

Disclosures. K Capriotti, K. P. Stewart, J. S. Pelletier and J. A. Capriotti are all inventors and patent holders of the technology described.

Compliance with ethics guidelines. All procedures followed were in accordance with the ethical standards of the responsible committee on human experimentation (institutional and national) and with the Helsinki Declaration of 1964, as revised in 2013. Informed consent was obtained from all patients for being included in the study.

Open Access. This article is distributed under the terms of the Creative Commons Attribution-NonCommercial 4.0 International License (http://creativecommons.org/licenses/ by-nc/4.0/), which permits any noncommercial use, distribution, and reproduction in any medium, provided you give appropriate credit to the original author(s) and the source, provide a link to the Creative Commons license, and indicate if changes were made.

\section{REFERENCES}

1. Warts FFF. Ferri's clinical advisor 2015: 5 books in 1 . Philadelphia: Mosby Elsevier; 2015. http://www. clinicalkey.com. Accessed March 12, 2015.

2. "Verruca Vulgaris" (Online). http://www.dermpath diagnostics.com/pages/DxRefDetail?catid=25\&id= 102. Accessed August 1, 2015.

3. "Warts, Nongenital" (Online) (2007). http:// emedicine.com/derm/topic457.htm. Accessed August 4, 2015.
4. Kwok CS, Holland R, Gibbs S. Efficacy of topical treatments for cutaneous warts: a meta-analysis and pooled analysis of randomized controlled trials. $\mathrm{Br} \mathrm{J}$ Dermatol. 2011;165(2):233-46.

5. Gibbs S, Harvey I, Sterling JC, Stark R. Local treatments for cutaneous warts. Cochrane Database Syst Rev. 2004;4:CD001781.

6. Gottardi W. Iodine and iodine compounds. In: Block SS, editor. Disinfection, sterilization, and preservation. 5th ed. Philadelphia, PA: Lippincott Williams \& Wilkins; 2001. p. 159-84.

7. Carroll B, Kevsin J, Steinmen ID. The mode of action of iodine on infectious agents. J Neward Beth-Israel Hosp. 1955;6(1):129.

8. Capriotti K, Capriotti JA. Topical iodophor preparations: chemistry, microbiology, and clinical utility. Dermatol Online J. 2012;18(11):1.

9. Oranje AP, de-Waard van der Spek SB. Update on common childhood skin infections. J Infect. 2015. (Epub ahead of print).

10. Dall'oglio F, D'Amico V, Nasca MR, Micali G. Treatment of cutaneous warts: an evidence-based review. Am J Clin Dermatol. 2012;13(2):73-96.

11. Parsad D, Saini R, Negi KS. Comparison of combination cimetidine and levamisole with cimetidine alone in the treatment of recalcitrant warts. Australas J Dermatol. 1999;40:93-5 (PubMed: 10333620).

12. Tucker SB, Ali A, Ransdell BL. Plantar wart treatment with combination imiquimod and salicylic acid pads. J Drugs Dermatol. 2003;2:1246 (PubMed: 12905977).

13. Muzio G, Massone C, Rebora A. Treatment of non-genital warts with topical imiquimod 5\% cream. Eur J Dermatol. 2002;12:347-9. (PubMed: 12095879).

14. Grussendorf-Conen EI, Jacobs S. Efficacy of imiquimod $5 \%$ cream in the treatment of recalcitrant warts in children. Pediatr Dermatol. 2002;19:263-6 (PubMed: 12047649).

15. Yazdanfar A, Farshchian M, Fereydoonnejad M, Farshchian M. Treatment of common warts with an intralesional mixture of 5-fluoruracil, lidocaine, and epinephrine; a prospective placebo-controlled, double-blind randomized trial. Dermatol Surg. 2008;34(5):656-9.

16. Alghamdi KM, Khurram H. Successful treatment of plantar warts with very diluted bleomycin using a translesional multipuncture technique: pilot 
prospective study. J Cutan Med Surg. 2012;16(4): 250-6.

17. Baciliere R, Marchese Johnson, S. Cutaneous Warts. An evidence-based approach to therapy. Am Fam Phys. 2005;72:647-652.

18. Dumville JC, McFarlane E, Edwards P, Lipp A, Holmes A, Liu Z. Preoperative skin antiseptics for preventing surgical wound infections after clean surgery. Cochrane Database Syst Rev. 2015;4: CD003949.

19. Capriotti K, Capriotti JA. Onychomycosis treated with a dilute povidone-iodine/dimethylsulfoxide preparation. Int Med Case Rep J. 2015;8:1-2.

20. Jaya C, Job A, Mathai E, Antonisamy B. Evaluation of topical povidone-iodine in chronic suppurative otitis media. Arch Otolaryngol Head Neck Surg. 2003;129(10):1098-100.
21. Isenberg SJ, Apt L, Valenton M, et al. A controlled trial of povidone-iodine to treat infectious conjunctivitis in children. Am J Ophthalmol. 2002;134(5):681-8.

22. Pelletier JS, Stewart K, Trattler W, Ritterband JC, Braverman S, Samson CM, Liang B, Capriotti JA. A combination povidone-iodine $0.4 \% /$ dexamethasone $0.1 \%$ ophthalmic suspension in the treatment of adenoviral conjunctivitis. Adv Ther. 2009;26(8):776-83.

23. Sauerbrei A, Wutzler P. Virucidal efficacy of povidone-iodine-containing disinfectants. Lett Appl Microbiol. 2010;51(2):158-63 (Epub 2010 May 14).

24. LaRocca R, LaRocca MAK. Microbiology of povidone-iodine-an overview. In: Degenis GA, Ansell J, editors. Proceedings of the international symposium on povidone. Lexington: University of Kentucky College of Pharmacy; 1983. p. 101-119. 